\title{
COMPUTING EDGE VERSION OF ECCENTRIC CONNECTIVITY INDEX OF NANOSTAR DENDRIMERS
}

\author{
Sara Mehdipour, Mehdi Alaeiyan, Ali Nejati* \\ Department of Mathematics, Karaj Branch, Islamic Azad University, Karaj, Iran \\ *Corresponding author; E-mail: a.nejati56@yahoo.com \\ (Received May 1, 2017; Accepted May 23, 2017)
}

\begin{abstract}
Let $\mathrm{G}$ be a molecular graph, the edge version of eccentric connectivity index of $G$ are defined as $\xi_{e}^{c}(G)=\sum_{f \in E(G)} \operatorname{deg}(f) \cdot \operatorname{ecc}(f)$, where $\operatorname{deg}(f)$ denotes the degree of an edge $f$ and $e c c(f)$ is the largest distance between $f$ and any other edge $g$ of $G$, namely, eccentricity of $f$. In this paper exact formulas for the edge version of eccentric connectivity index of two classes of nanostar dendrimers were computed.
\end{abstract}

Keywords: edge eccentric connectivity index, nanostar dendrimers, topological index.

\section{INTRODUCTION}

Molecular descriptors are playing significant role in chemistry, pharmacology, etc. Among them, topological indices have a prominent place (TODESCHINI and CONSONNI, 2000). There are numerous of topological descriptors that have found some applications in theoretical chemistry, especially in QSPR/QSAR research.

More recently, a new topological index, eccentric connectivity index, has been investigated. This topological model has been shown to give a high degree of predictability of pharmaceutical properties and may provide leads for the development of safe and potent antiHIV compounds. We encourage the reader to consult papers (SHARMA et al.,1997; SARDANA and MADAN, 2001, 2002; LATHER and MADAN, 2005; DUREJA and MADAN, 2005, 2006, 2009; KUMAR and MADAN, 2007) for some applications and papers (MORGAN et al., 2010; ZHOU, 2010; ASHRAFI et al., 2011; ILIĆ and GUTMAN, 2011) for the mathematical properties of this topological index.

Dendrimers are highly branched macromolecules. They are being investigated for possible uses in nanotechnology, gene therapy, and other fields. Each dendrimer consists of a multifunctional core molecule with a dendritic wedge attached to each functional site. The core molecule without surrounding dendrons is usually referred to as zeros generation. Each successive repeat unit along all branches forms the next generation, 1st generation and 2nd generation and so on until the terminating generation. The topological study of these macromolecules is the aim of this article, see (ASHRAFI and MIRZARGAR, 2008; KHORAMDEL et al., 2008; YOUSEFI-AZARI et al., 2008; KARBASIOUN and ASHRAFI, 2009) for details. 
Now, we introduce some notation and terminology. Let $G$ be a graph with vertex set $V(G)$ and edge set $E(G)$. Let $\operatorname{deg}(u)$ denote the degree of the vertex $u$ in $G$. If $\operatorname{deg}(u)=1$, then $u$ is said to be a pendent vertex. An edge incident to a pendent vertex is said to be a pendent edge. For two vertices $u$ and $v$ in $V(G)$, we denote by $d(u, v)$ the distance between $u$ and $v$, i.e., the length of the shortest path connecting $u$ and $v$. The eccentricity of a vertex $u$ in $V(G)$, denoted by $\operatorname{ecc}(u)$, is defined to be

$$
\operatorname{ecc}(u)=\max \{d(u, v) \mid v \in V(G)\}
$$

The diameter of a graph $G$ is defined to be $\max \{\operatorname{ecc}(u) \mid u \in V(G)\}$. The eccentric connectivity index, $\xi^{c}(G)$, of a graph $G$ is defined as

$$
\xi^{c}(G)=\sum_{u \in V(G)} \operatorname{deg}(u) \cdot \operatorname{ecc}(u)
$$

where $\operatorname{deg}(u)$ is the the degree of a vertex $u$ and $\operatorname{ecc}(u)$ is its eccentricity. Let $f=u v$ be an edge in $E(G)$. Then the degree of the edge $f$ is defined to be $\operatorname{deg}(u)+\operatorname{deg}(v)-2$. For two edges $f_{1}=u_{1} v_{1}, f_{1}=u_{2} v_{2}$ in $E(G)$, the distance between $f_{1}$ and $f_{2}$, denoted by $d\left(f_{1}, f_{2}\right)$, is defined to be

$d\left(f_{1}, f_{2}\right)=\min \left\{d\left(u_{1}, u_{2}\right), d\left(u_{1}, v_{2}\right), d\left(v_{1}, u_{2}\right), d\left(v_{1}, v_{2}\right)\right\}$. The eccentricity of an edge $f$, denoted by $\operatorname{ecc}(f)$, is defined as

$$
e c c(f)=\max \{d(f, e) \mid e \in E(G)\}
$$

The edge eccentric connectivity index of $G$ (XU and GUO, 2012), denoted by $\xi_{e}^{c}(G)$, is defined as

$$
\xi_{e}^{c}(G)=\sum_{f \in E(G)} \operatorname{deg}(f) \cdot e c c(f)
$$

The second and third author of this paper in some joint works computed the edge version of modified eccentric connectivity index of some molecular graphs (NEJATI and ALAEIYAN, 2014, 2015). In this paper exact formulas for the edge version of eccentric connectivity index of two classes nanostar dendrimers were computed.

\section{MAIN RESULT AND DISCUSION}

Suppose $N S(n)$ denotes the molecular graph of a dendrimer with exactly $n$ generations depicted in Figure 1. The eccentric connectivity index of $N S(n)$ were obtained in (ASHRAFI and SAHELI, 2012). In the following theorem we calculate the edge eccentric connectivity index of $N S(n)$. 


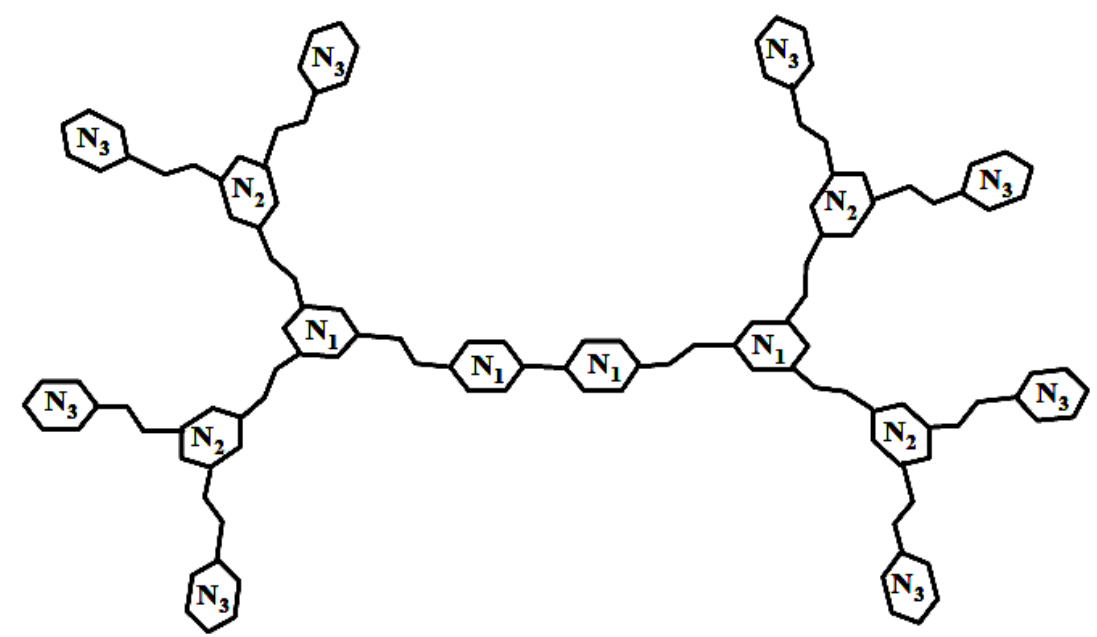

Figure 1. The molecular graph of $N S(3)$.

Theorem 1. The edge eccentric connectivity index of $N S(n)$ is computed as

$$
\xi_{e}^{c}(N S(n))=\left(480 \times 2^{n}-80\right) n-22 \times 2^{n}+168 .
$$

Proof. Considering Figure 2 and Table 1 we have $5 n+5$ types of edges in $N S(n)$, based on their eccentricities. We have $2^{n+1}$ numbers of edges of type 1 with maximum eccentricity equals to $10 n+7$ (red edges). Also we have $2^{n+1}$ numbers of edges of types 2,3 with eccentricity equals to $10 n+6$ and $10 n+5$ respectively. The number of edges of type 4 is $2^{n}$ and their eccentricity is $10 n+4$ and so it continues until we have 4 edges of type $5 n+4$ with eccentricity equals to $5 n+4$ and finally there is one edge of type $5 n+5$ with minimum edge eccentric connectivity equals to $5 n+3$ (blue edge). Also it is clear that for any edge $u$ in $N S(n), \operatorname{deg}(u)=2$ or $\operatorname{deg}(u)=3$ except the last type of edges with minimum eccentricity such that it's degree is 4 . (See Table 1).

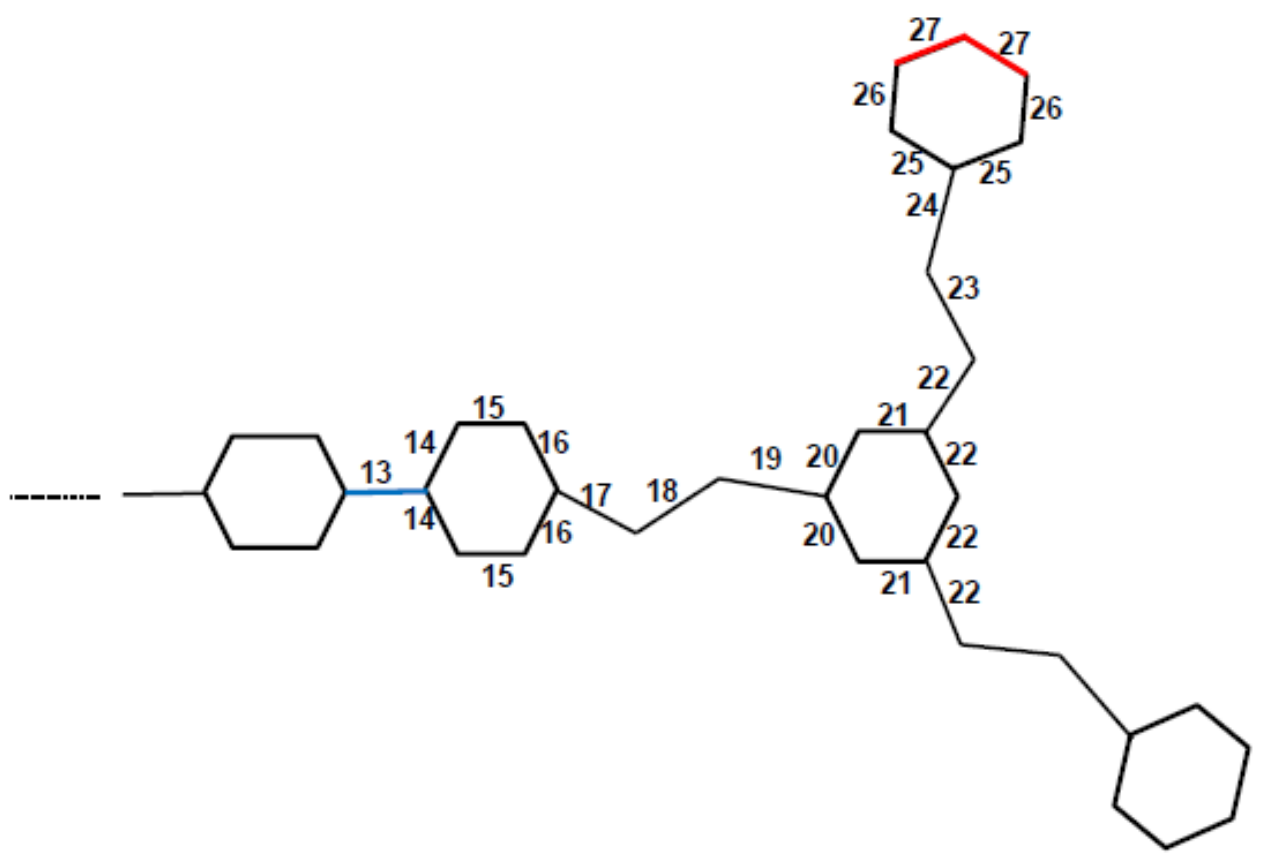

Figure 2. The eccentricity of edges in a half of $N S(2)$. 
Therefore, we have

$$
\begin{gathered}
\xi_{e}^{c}(N S(n))=\sum_{f \in E(G)} \operatorname{deg}(f) \cdot e c c(f)=2^{n+1} \times 2 \times(10 n+7)+2^{n+1} \times 2 \times(10 n+6) \\
2^{n+1} \times 3 \times(10 n+5)+\sum_{k=1}^{n-1}\left(\frac{2^{n}}{2^{k-1}} \times 3 \times(10 n-5 k+9)\right) \\
+\sum_{k=1}^{n-1}\left(\frac{2^{n}}{2^{k-1}} \times 2 \times(10 n-5 k+8)\right)+\sum_{k=1}^{n-1}\left(\frac{2^{n+1}}{2^{k-1}} \times 3 \times(10 n-5 k+7)\right) \\
+\sum_{k=1}^{n-1}\left(\frac{2^{n}}{2^{k-1}} \times 3 \times(10 n-5 k+6)\right)+\sum_{k=1}^{n-1}\left(\frac{2^{n}}{2^{k-1}} \times 3 \times(10 n-5 k+5)\right) \\
+(2)(3)(5 n+9)+(2)(2)(5 n+8)+(2)(3)(5 n+7)+(4)(3)(5 n+6)+(4)(2)(5 n+5) \\
+(4)(3)(5 n+4)+(1)(4)(5 n+3) .
\end{gathered}
$$

\begin{tabular}{|c|c|c|c|}
\hline $\begin{array}{l}\text { Types of } \\
\text { edges }\end{array}$ & Num & $\operatorname{ecc}(\mathbf{f})$ & $\operatorname{deg}(f)$ \\
\hline 1 & $2^{n+1}$ & $10 n+7$ & 2 \\
\hline 2 & $2^{n+1}$ & $10 n+6$ & 2 \\
\hline 3 & $2^{n+1}$ & $10 n+5$ & 3 \\
\hline 4 & $2^{n}$ & $10 n+4$ & 3 \\
\hline 5 & $2^{n}$ & $10 n+3$ & 2 \\
\hline 6 & $2^{n+1}$ & $10 n+2$ & 3 \\
\hline .. & ... & .. & ... \\
\hline $5 n-2$ & 4 & $5 n+10$ & 3 \\
\hline $5 n-1$ & 2 & $5 n+9$ & 3 \\
\hline $5 n$ & 2 & $5 n+8$ & 2 \\
\hline $5 n+1$ & 2 & $5 n+7$ & 3 \\
\hline $5 n+2$ & 4 & $5 n+6$ & 3 \\
\hline $5 n+3$ & 4 & $5 n+5$ & 2 \\
\hline $5 n+4$ & 4 & $5 n+4$ & 3 \\
\hline $5 n+5$ & 1 & $5 n+3$ & 4 \\
\hline
\end{tabular}

Thus, we have

$$
\xi_{e}^{c}(N S(n))=\left(480 \times 2^{n}-80\right) n-22 \times 2^{n}+168 .
$$

Then this proof is completed.

Table 1. Types of edges in $N S(n)$. 


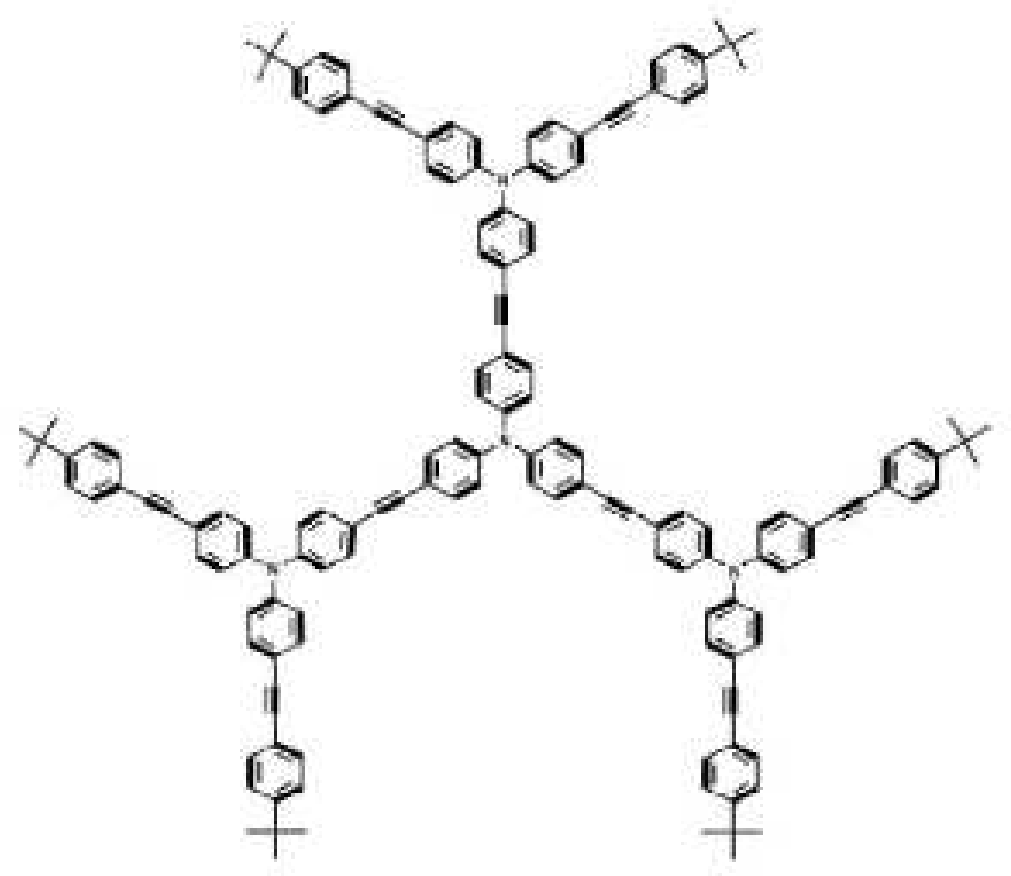

Figure 3. The molecular graph of $N S B(1)$.

One type of nanostar dendrimers is N-branched phenylacetylenes and it is shown by $\operatorname{NSB}(n)$, some topological indices were obtained in (YARAHMADI and FATH-TABAR, 2011; YARAHMADI, 2010). In Figure 3, the molecular graph of $N S B(n)$ are shown. In Theorem 2 we obtain the edge eccentric connectivity index of $\operatorname{NSB}(n)$.

Theorem 2. The edge eccentric connectivity index of $N S B(n)$ is computed as

$$
\xi_{e}^{c}(N S B(n))=\left(5292 \times 2^{n}-1188\right) n+1593 \times 2^{n}+660 .
$$

Proof. Considering Figure 4 and Table 2, it can be seen that, we have $9 n+10$ types of edges in $N S B(n)$, based on their eccentricities. We have $9 \times 2^{n}$ numbers of edges of type 1 with maximum eccentricity equals to $18 n+18$ (red edges). Also we have $3 \times 2^{n}$ numbers of edges of types 2 with eccentricity equals to $18 n+17$ and $3 \times 2^{n+1}$ numbers of edges are of type 3 and the eccentricity of them equals to $18 n+16$. The number of edges of type 4 is $3 \times 2^{n+1}$ and their eccentricity is $18 n+15$ and so it continues until we have 6 edges of type $9 n+9$ with eccentricity equals to $9 n+10$ and finally there are three edges of type $9 n+10$ with minimum edge eccentric connectivity equals to $9 n+9$ (blue edges). Also it is clear that for any edge $u$ in $N S B(n), \operatorname{deg}(u)=2$ or $\operatorname{deg}(u)=3$ or $\operatorname{deg}(u)=4$ except the edges of type two such that the degree of each of them is 5. (See Table 2). Therefore, we have

$$
\begin{aligned}
\xi_{e}^{c}(N S B(n))= & \sum_{f \in E(G)} \operatorname{deg}(f) \cdot e c c(f)=9 \times 2^{n} \times 3 \times(18 n+18)+3 \times 2^{n} \times 5 \times(18 n+17) \\
+ & \sum_{k=1}^{n}\left(\frac{3 \times 2^{n-1}}{2^{k-1}} \times 4 \times(18 n-9 k+17)\right)+\sum_{k=1}^{n+1}\left(\frac{3 \times 2^{n+1}}{2^{k-1}} \times 3 \times(18 n-9 k+25)\right) \\
+ & \sum_{k=1}^{n+1}\left(\frac{3 \times 2^{n+1}}{2^{k-1}} \times 2 \times(18 n-9 k+24)\right)+\sum_{k=1}^{n+1}\left(\frac{3 \times 2^{n+1}}{2^{k-1}} \times 3 \times(18 n-9 k+23)\right) \\
& +\sum_{k=1}^{n+1}\left(\frac{3 \times 2^{n}}{2^{k-1}} \times 4 \times(18 n-9 k+22)\right)+\sum_{k=1}^{n+1}\left(\frac{3 \times 2^{n+1}}{2^{k-1}} \times 3 \times(18 n-9 k+21)\right)
\end{aligned}
$$




$$
\begin{aligned}
+\sum_{k=1}^{n+1}\left(\frac{3 \times 2^{n+1}}{2^{k-1}} \times 2 \times\right. & (18 n-9 k+20))+\sum_{k=1}^{n+1}\left(\frac{3 \times 2^{n+1}}{2^{k-1}} \times 3 \times(18 n-9 k+19)\right) \\
& +\sum_{k=1}^{n+1}\left(\frac{3 \times 2^{n}}{2^{k-1}} \times 4 \times(18 n-9 k+18)\right) .
\end{aligned}
$$

Thus, we have

$$
\xi_{e}^{c}(N S B(n))=\left(5292 \times 2^{n}-1188\right) n+1593 \times 2^{n}+660 .
$$

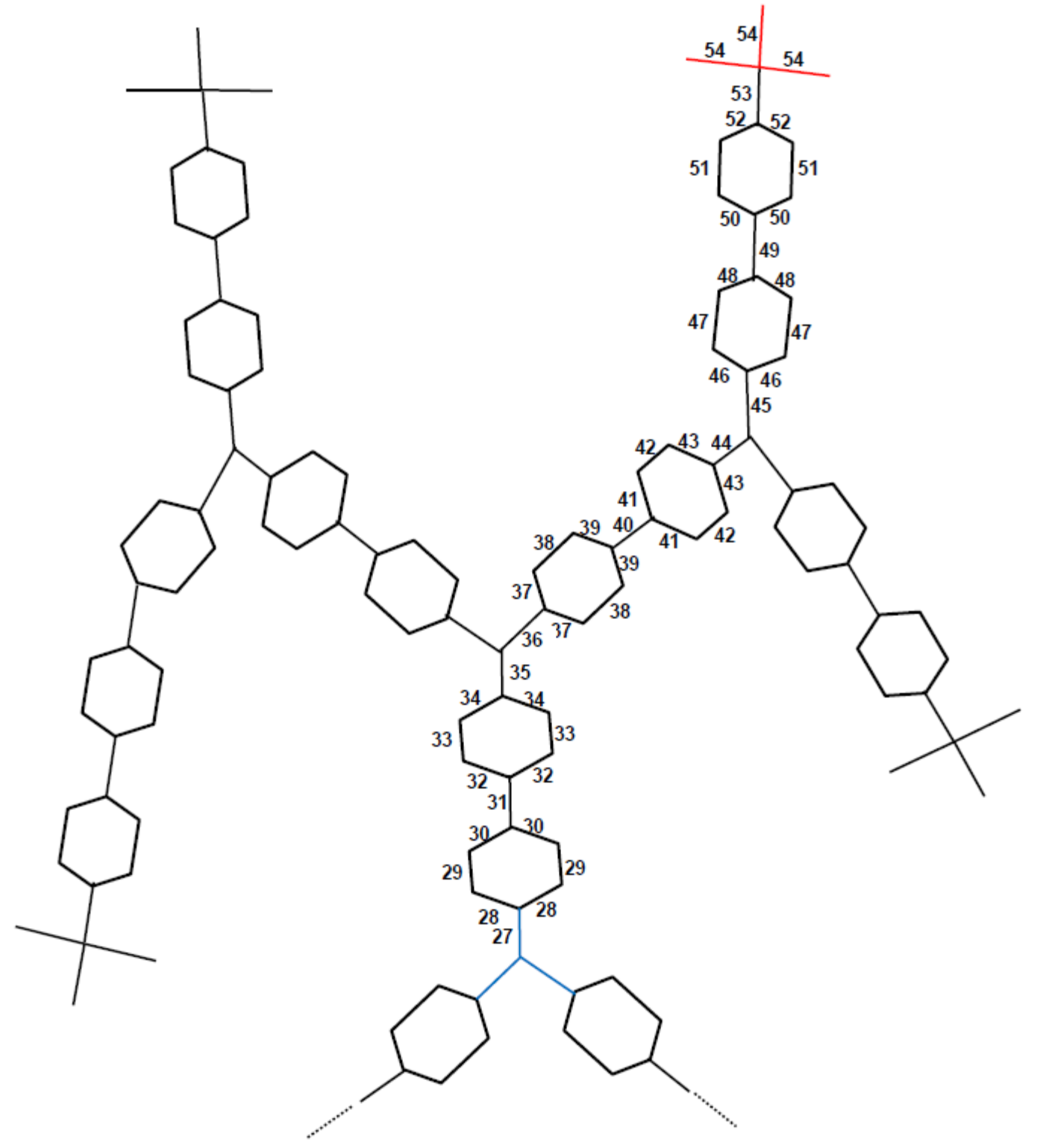

Figure 4. The eccentricity of edges in a third of $N S B(2)$.

Then this proof is completed. 
Table 2. Types of edges in $\operatorname{NSB}(n)$.

\begin{tabular}{cccc}
\hline $\begin{array}{c}\text { Types of } \\
\text { edges }\end{array}$ & Num & $\operatorname{ecc}(\mathbf{f})$ & $\operatorname{deg}(\mathbf{f})$ \\
\hline $\mathbf{1}$ & $2^{n} \times 9$ & $18 n+18$ & $\mathbf{3}$ \\
$\mathbf{2}$ & $2^{n} \times 3$ & $18 n+17$ & $\mathbf{5}$ \\
$\mathbf{3}$ & $2^{n+1} \times 3$ & $18 n+16$ & $\mathbf{3}$ \\
$\mathbf{4}$ & $2^{n+1} \times 3$ & $18 n+15$ & $\mathbf{2}$ \\
$\mathbf{5}$ & $2^{n+1} \times 3$ & $18 n+14$ & $\mathbf{3}$ \\
$\mathbf{6}$ & $2^{n} \times 3$ & $18 n+13$ & $\mathbf{4}$ \\
$\ldots$ & $\ldots$ & $\ldots$ & $\ldots$ \\
$\mathbf{9 n + 7}$ & $\mathbf{6}$ & $9 n+12$ & $\mathbf{3}$ \\
$\mathbf{9 n}+\mathbf{8}$ & $\mathbf{6}$ & $9 n+11$ & $\mathbf{2}$ \\
$\mathbf{9 n}+\mathbf{9}$ & $\mathbf{6}$ & $9 n+10$ & $\mathbf{3}$ \\
$\mathbf{9 n + 1 0}$ & $\mathbf{3}$ & $9 n+9$ & $\mathbf{4}$ \\
\hline
\end{tabular}

\section{References:}

[1] AShrafi, A.R., Doslic, T., SAHELI, M. (2011): The eccentric connectivity index of TUC4C8(R) nanotubes. MATCH Commun. Math. Comput. Chem. 65: 221-230.

[2] Ashrafi, A.R., SAHELI, M. (2012): Computing Eccentric Connectivity Index of a Class of Nanostar Dendrimers. Kragujevac J. Sci. 34: 65-70.

[3] Ashrafi, A. R., MirZargar, M. (2008): Szeged and edge Szeged indices of an infinite family of nanostar dendrimers. Indian J. Chem. 47A: 538-541.

[4] DUREJA, H., MADAN, A.K. (2005): Topochemical models for prediction of cyclindependent kinase 2 inhibitory activity of indole-2-ones. J. Mol. Model. 11: 525531. doi: 10.1111/j.1747-0285.2008.00766.x

[5] DuREJA, H., MADAN, A.K. (2006): Topochemical models for the prediction of permeability through blood-brain barrier. Int. J. Pharm. 323 (1-2): 27-33. doi: 10.1016/j/ijpharm.2006.05.042.

[6] DuREJA, H., MADAN, A.K. (2009): Predicting anti-HIV activity of dimethylaminopyridin-2-ones: Computational approach using topochemical descriptors. Chem. Biol. Drug Des. 73 (2): 258-270. doi: 10.1111/j.1747-0285.2008.00766.x

[7] ILIć, A., GuTMAn, I. (2011): Eccentric connectivity index of chemical trees. MATCH Commun. Math. Comput. Chem. 65: 731-744.

[8] Karbasioun, A., ASHRAFi, A.R. (2009): Wiener and Detour Indices of o New Type of Nanostar Dendrimers. Macedonian Journal of Chemistry and Chemical Engineering 28 (1): 49-54. doi: 10.20450/mjcce.2009.221

[9] Khalifeh, M.H, Yousefi-Azari, H., Ashrafi, A.R. (2008): Computing Wiener and Kirchhoff indices of a triangulane. Indian J. Chem. 47A (10): 1503-1507.

[10] Kumar, V., MADAN, A.K. (2006): Application of graph theory: Prediction of cytosolic phospholipase A(2) inhibitory activity of propan-2-ones. J. Math. Chem. 39 (3-4): 511521. doi: 10.1007/s10910-005-9036-y

[11] KUMAR, V., MADAN, A.K. (2007): Application of graph theory: Models for prediction 
of carbonic anhydrase inhibitory activity of sulfonamides. J. Math. Chem. 42 (4): 925940. doi: 10.1007/s10910-006-9149-y

[12] LATHER, V., MADAN, A.K. (2005): Application of graph theory: Topological models for prediction of CDK-1 inhibitory activity of aloisines. Croat. Chem. Acta 78 (1): 5561.

[13] Morgan, M.J., Mukwembi, S., Swart, H.C. (2010): On the eccentric connectivity index of a graph. Disc. Math. 311 (13): 1229-1234. doi: 10.1016/j.disc.2009.12.013

[14] Nejati, A., Alaeiyan, M. (2014): The edge version of MEC index of one-pentagonal carbon nanocones. Bulgarian Chemical Communications, 46 (3): 462-464.

[15] Nejati, A., AlaeiYan, M. (2015): The edge version of MEC index of linear polycene parallelogram benzenoid. Optoelectronics and Advanced Materials - Rapid Communications 9 (5-6): 813-815.

[16] SardanA, S., Madan, A.K. (2001): Application of graph theory: Relationship of molecular connectivity index, Wiener index and eccentric connectivity index with diuretic activity. MATCH Commun. Math. Comput. Chem. 43: 85-98.

[17] SaRdanA, S., MadAn, A.K. (2002): Application of graph theory: Relationship of antimycobacterial activity of uinolone derivatives with eccentric connectivity index and Zagreb group parameters. MATCH Commun. Math. Comput. Chem. 45: 35-53.

[18] Sharma, V., Goswami, R., Madan, A.K., (1997): Eccentric connectivity index: A novel highly discriminating topological descriptor for structure-property and structureactivity studies. J. Chem. Inf. Model. 37 (2): 273-282.

[19] Todeschini, R., Consonni, V. (2000): Handbook of Molecular Descriptors. Methods and Principles in Medicinal Chemistry Series. Volume 11. Wiley-VCH, Weinheim and New York.

[20] Xu, X., GuO, Y. (2012): The Edge Version of Eccentric Connectivity Index. International Mathematical Forum 7 (6): 273-280.

[21] Yarahmadi, Z., FATh-TABAR, G.H. (2011): The Wiener, Szeged, PI, vertex PI, the First and Second Zagreb Indices of N-branched Phenylacetylenes Dendrimers. MATCH Commun. Math. Comput. Chem. 65 (1): 201-208.

[22] YARAHMADI, Z. (2010): Eccentric Connectivity and Augmented Eccentric Connectivity Indices of N-Branched Phenylacetylenes Nanostar Dendrimers. Iranian Journal of Mathematical Chemistry 1 (2): 105-110. doi: 10.22052/ijmc.2010.5160

[23] Yousefi-AZAri, H., Ashrafi, A.R., BAhrami, A., YAZDANI, J. (2008): Computing Topological Indices of Some Types of Benzenoid Systems and Nanostars. Asian. J. Chem. 20 (1): 15-20.

[24] Zhou, B. (2010): On eccentric connectivity index. MATCH Commun. Math. Comput. Chem. 63: 181-198. 